\title{
Green synthesis of silver nanoparticles from Tectona grandis seeds extract: characterization and mechanism of antimicrobial action on different microorganisms
}

\author{
Akhil Rautela*, Jyoti Rani and Mira Debnath (Das)
}

\begin{abstract}
Green synthesis of silver nanoparticles makes use of plant constituents, like carbohydrates, fats, enzymes, flavonoids, terpenoids, polyphenols, and alkaloids, as reducing agents to synthesize silver nanoparticles. The present study for the first time utilized seed extract of Tectona grandis (teak) for reduction of $1 \mathrm{mM}$ silver nitrate solution to silver nanoparticles. The method proved to be very simple, cost-efficient, and convenient. Synthesis of nanoparticles was confirmed by visual detection in which the colorless solution gets changed to a brown-colored solution. Further characterization was done by UV-visible spectroscopy, XRD, FTIR analysis, SEM/EDS, FESEM, and TEM. Size of silver nanoparticles was found to be 10-30 nm approximately as determined by transmission electron microscopy (TEM). Energy-dispersive spectra (EDS) revealed that nanoparticles contain silver in its pure form. Well diffusion method showed the antimicrobial effect of AgNPs on different microorganisms with the zone of inhibition of $16 \mathrm{~mm}$ for Staphylococcus aureus, $12 \mathrm{~mm}$ for Bacillus cereus, and $17 \mathrm{~mm}$ for E. coli when $50 \mathrm{\mu g}$ of AgNPs was used. Minimum inhibitory concentration was found to be $5.2,2.6$, and $2.0 \mu \mathrm{g} / \mathrm{ml}$ for Bacillus cereus, Staphylococcus aureus, and E. coli respectively. Mode of action of antimicrobial activity of nanoparticles was investigated by determining leakage of reducing sugars and proteins, suggesting that AgNPs were able to destroy membrane permeability.
\end{abstract}

Keywords: Silver nanoparticles, Green synthesis, Characterization, Antimicrobial activity

\section{Introduction}

Nanotechnology is the process of synthesizing particles which are in the nano range, ranging from approximately 1 to $100 \mathrm{~nm}$. They have large surface area to volume ratio due to which they possess optical properties as they are small enough to confine their electrons and produce quantum effects by which their detection becomes easy. Intensive research is being done on silver nanoparticles (AgNPs) owing to their wide range of applications in medical devices (He et al. 2013), pharmaceuticals (Kumar et al. 2011), clothing (Vigneshwaran et al. 2007a), and water purification (Lin et al. 2013) due to their antimicrobial properties and also in adsorption of metals

\footnotetext{
* Correspondence: akhilr.bce15@iitbhu.ac.in

School of Biochemical Engineering, Indian Institute of Technology (BHU), Varanasi, India
}

and pesticides (Asthana et al. 2016; Das et al. 2012), sensing of food adulterants (Ping et al. 2012), detection of DNA (Thompson et al. 2008), etc.

Chemical reduction which is the most commonly used method for synthesis of nanoparticles uses an organic solvent, like ethylene glycol (Wiley et al. 2004), and reducing agents, like hydrazine (Guzmán et al. 2009), sodium borohydride (Song et al. 2009), trisodium citrate (Rashid et al. 2013), and ascorbate (Qin et al. 2010). There was an earnest need for the development of cleaner and safer methods as chemical reduction gives low yield, requires complicated purification and high energy. This gave rise to green synthesis which utilizes microorganisms (bacteria (Natarajan et al. 2010), fungi (Vigneshwaran et al. 2007b), yeast (Kowshik et al. 2002), actinomycetes (Sastry et al. 2003)) and plant extracts for the reduction 
of silver to silver nanoparticles. Synthesis of nanoparticles from microbes can be extracellular (Kowshik et al. 2002) or intracellular (Mukherjee et al. 2001). The major disadvantage of the use of microbial source is the maintenance of aseptic conditions, high cost of isolation, and their maintenance in culture media due to which plants promise to be excellent sources for reducing agents for the synthesis of nanoparticles. Parts of plants used for synthesis of AgNPs are leaf (Prakash et al. 2013), bark (Sathishkumar et al. 2009), seeds (Bar et al. 2009), roots (Suman et al. 2013), etc. There are numerous examples of AgNPs synthesis from diverse plant sources, like Chrysanthemum morifolium (He et al. 2013), Cassia auriculata (Kumar et al. 2011), Mimusops elengi (Prakash et al. 2013), Cinnamon zeylanicum (Sathishkumar et al. 2009), Jatropha curcas (Bar et al. 2009), and Morinda citrifolia (Suman et al. 2013). Constituents of plants, like carbohydrates, fats, enzymes, flavonoids, terpenoids, polyphenols, and alkaloids, are capable of reducing silver to nanoparticles.

Antimicrobial activity of silver nanoparticles has been reported in many research papers. The mechanism of antibacterial action of silver nanoparticles is a topic of debate and is not well understood. But many assumptions and theories are there. In one of the study on E. coli and Staphylococcus aureus, it was seen that silver ions get released by nanoparticles and accumulate around the cell wall or inside the cell and affect DNA replication and interact with thiol groups of protein, inducing protein inactivation (Feng et al. 2000). This also leads to the formation of reactive oxygen species (Matsumura et al. 2003).

Tectona grandis, commonly called as timber, teak, Sagun, has potential medicinal value. It is widely used for making furniture, cabinets, and musical instruments (Indira and Mohanadas 2002). Its bark has an antibacterial compound 5-hydroxy-1,4-naphthalenedione (Juglone) which shows antibacterial activity against Listeria monocytogenes and methicillin-resistant Staphylococcus aureus (MRSA) (Neamatallah et al. 2005). It is also used for the treatment of anemia and shows anti-hemolytic anemia activity (Diallo et al. 2008). Its seeds are acclaimed to be hair tonic, which is reported to increase the number of hair follicles in the anagenic phase (Jaybhaye et al. 2010). Its leaves, bark, and wood show antioxidant properties, with wood showing the highest (98.6\%) inhibition against DPPH (Krishna and Jayakumaran 2010).

In the present study, Tectona grandis seed extract was utilized for the reduction of silver nitrate to silver nanoparticles, and characterization of the synthesized nanoparticles was carried out by UV-visible spectroscopy, scanning electron microscope (SEM), energydispersive X-ray spectroscopy (EDX), field emission scanning electron microscope (FESEM), transmission electron microscope (TEM), X-ray diffraction (XRD), and Fourier transform infrared spectroscopy (FT-IR) analysis. Antimicrobial activity of the synthesized nanoparticles was investigated against representative human pathogenic microorganisms (Bacillus cereus, Staphylococcus aureus, and Escherichia coli). Minimum inhibitory concentration of silver nanoparticles against these microorganisms was determined. Besides, the mechanism of action of antimicrobial activity was understood by detecting leakage of reducing sugars and proteins through DNS and Bradford's method, which indicated that killing of microorganisms was through the destruction of membranous structure and permeability.

\section{Materials and methods Materials}

Tectona grandis seeds were collected from BHU campus. Before washing, the outer covering of the harvested seeds was removed. Seeds were dried at room temperature for 3-4 days so that moisture gets removed completely. Dried seeds were crushed to fine powder and stored in dry and airtight container for further use. Silver nitrate $\left(\mathrm{AgNO}_{3}\right)$ was purchased from SRL, India. All other reagents were of analytical grade and used as received. All the solutions were freshly prepared with double distilled water for the
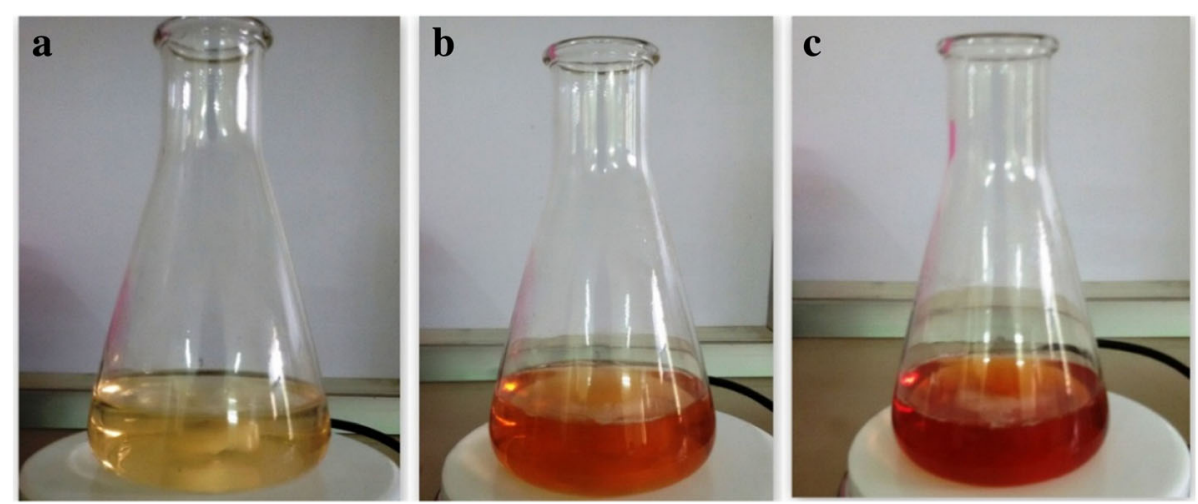

Fig. 1 Visual detection [(a) 0 min. (b) $30 \mathrm{~min}$. (c) $1 \mathrm{~h}]$ 


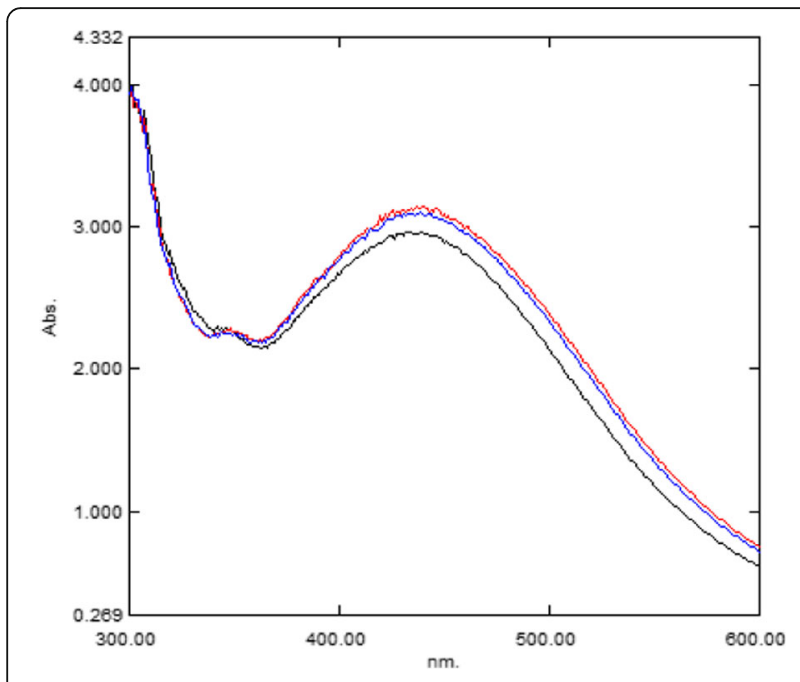

Fig. 2 Absorption spectra of silver nanoparticles obtained at different time intervals

experimental procedure and were kept in the dark to avoid any photochemical reaction.

\section{Microorganisms}

Antimicrobial activity of silver nanoparticles was investigated against Gram-positive bacteria (Bacillus cereus; MTCC 9817 and Staphylococcus aureus; MTCC 7443) and Gram-negative bacteria (Escherichia coli; MTCC 443). Nutrient agar containing peptone, beef extract, and $\mathrm{NaCl}$ was used to maintain bacterial strains. Prior to the experiment, bacterial strains were inoculated in nutrient broth to encourage the growth of microorganisms in the exponential phase.

\section{Tectona grandis seed extract preparation}

Five grams of seed powder was carefully weighed and added in an Erlenmeyer flask of $250 \mathrm{ml}$ containing $50 \mathrm{ml}$

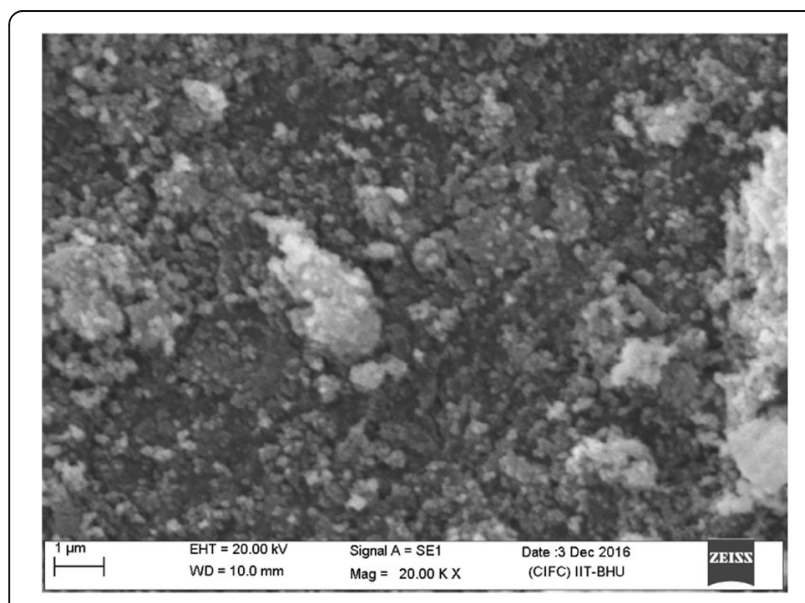

Fig. 3 SEM image of AgNPS

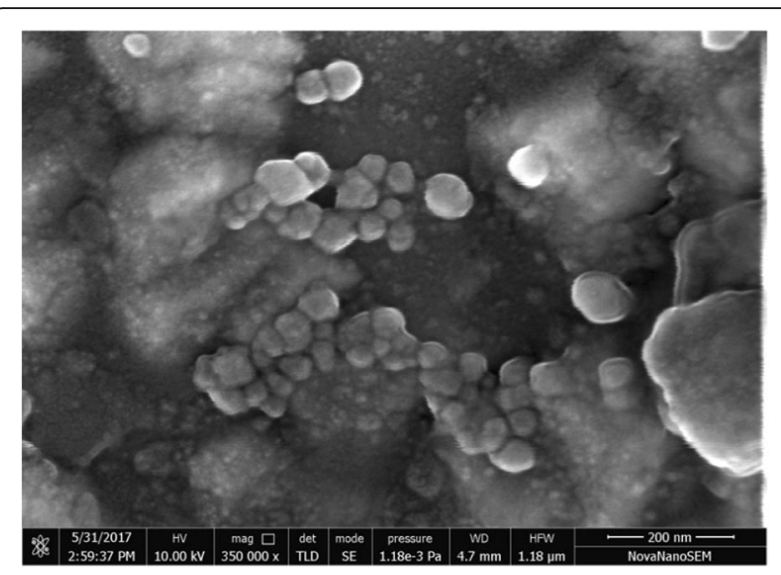

Fig. 4 FESEM image of AgNPs

of double distilled water. The mixture in the flask was heated in a water bath for $15-20 \mathrm{~min}$ at $80^{\circ} \mathrm{C}$. After boiling, the extract was filtered using a muslin cloth to remove any coarse material. Volume was made up to $100 \mathrm{ml}$ using double distilled water. The prepared extract was stored at $4{ }^{\circ} \mathrm{C}$ and used within 1 week.

\section{Synthesis of silver nanoparticles using seed extract}

$1 \mathrm{mM}$ silver nitrate solution in double distilled water was the source of silver. Silver nitrate and seed extract were mixed together in a ratio of 1:9. The reaction mixture was heated below the boiling point and continuously stirred at $800 \mathrm{rpm}$ using magnetic stirrer. The mixture turned reddish brown in color within $1 \mathrm{~h}$. The whole reaction was carried out in the dark. The obtained suspension of $\mathrm{Ag} / T$. grandis was centrifuged at $15,000 \mathrm{rpm}$ for $45 \mathrm{~min}$. The pellet containing silver nanoparticles was washed 3-4 times with deionized water to remove silver ions and seed extract residue. The precipitated nanoparticles were lyophilized. Lyophilized nanoparticles were stored in a cool, dry, and dark place and further their characterization was carried out.

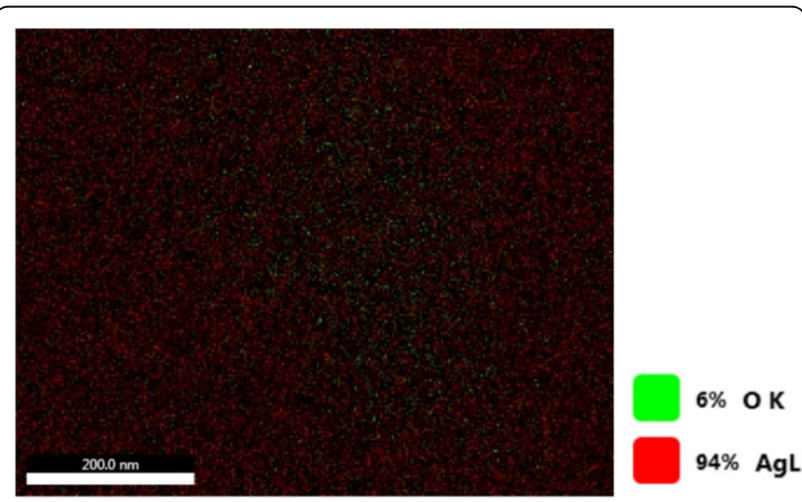

Fig. 5 FESEM mapping 


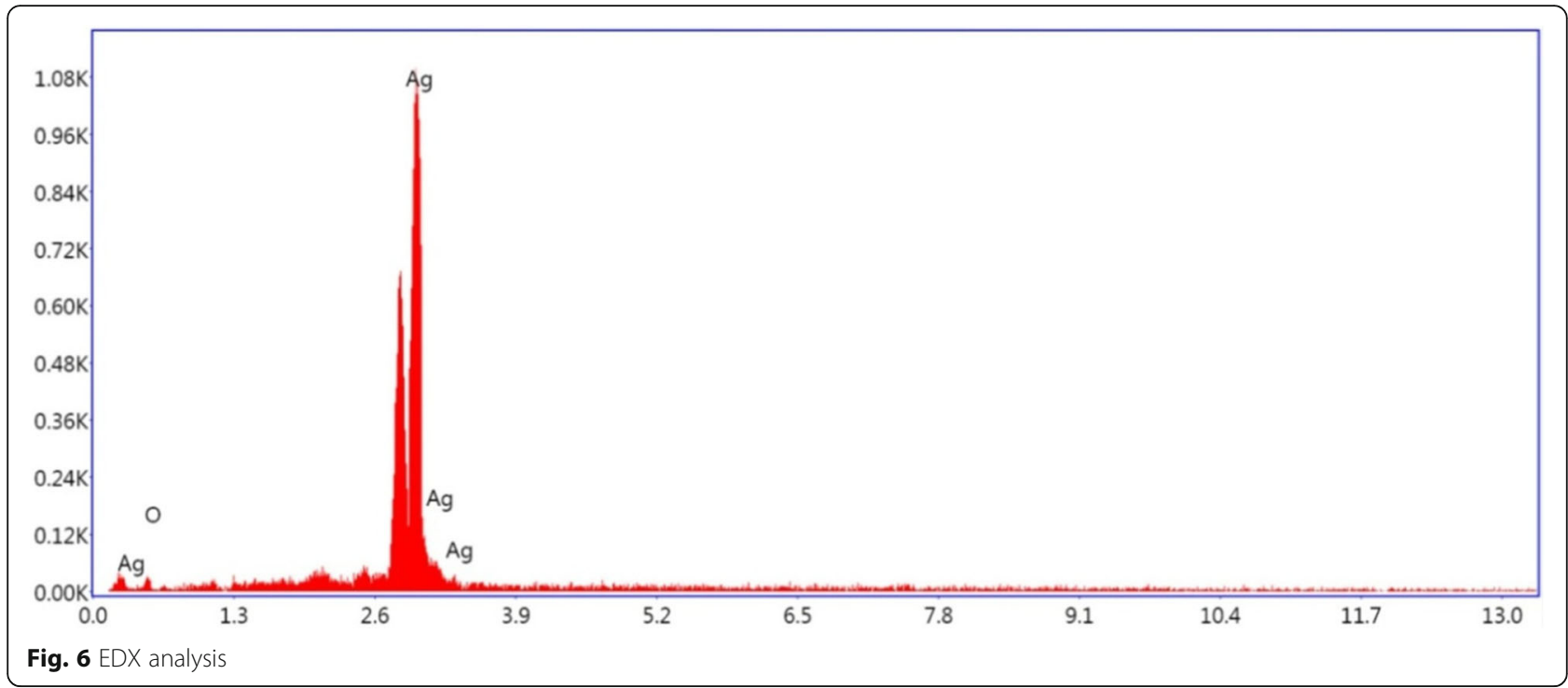

\section{Characterization of synthesized nanoparticles}

UV-1800 Shimadzu spectrophotometer was used to obtain UV-visible spectra of AgNPs at different time intervals using seed extract diluted with water (1:9) as a blank. Further shape and size of formed nanoparticles were determined by SEM, FESEM equipped with EDS, and TEM. A lyophilized sample of AgNPs was subjected to Zeiss EVO-18 scanning electron microscope at $20 \mathrm{kV}$ to study the morphological features of silver nanoparticles. Further, the shape, morphology, and elemental mapping of AgNPs were studied using field emission scanning electron microscopy (NOVA NanoSEM 450). For this purpose, the lyophilized sample was

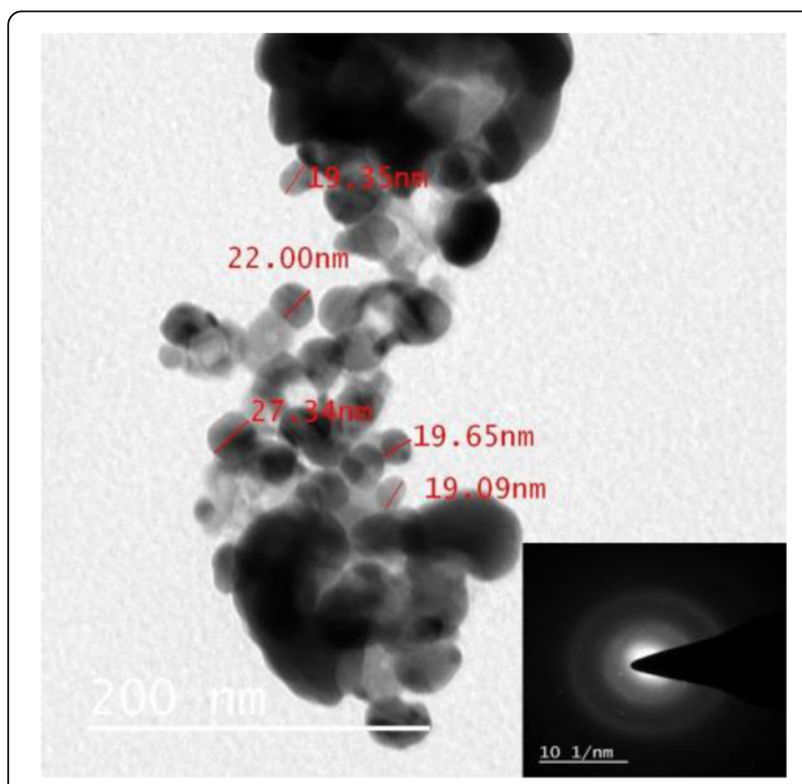

Fig. 7 TEM image of AgNPs (inset shows the SAED pattern of nanocrystalline silver) sonicated for a sufficient amount of time, the smear was made on a platinum grid, and allowed to dry overnight under vacuum. The grid was then coated with a thin film of palladium and finally subjected to FESEM. Transmission electron microscopy was done to exactly determine the size of nanoparticles. Sonicated sample was loaded on a carbon-coated copper grid and was allowed to dry overnight in a vacuum and subjected to transmission electron microscopy (FEI-TECNAI G ${ }^{2} 20$ TWIN). The crystalline nature of AgNPs was confirmed by XRD pattern obtained from Rigaku-MiniFlex $600 \mathrm{X}$-ray diffractometer at $2 \theta$ range from 0 to $100^{\circ}$. The sample for XRD measurement was prepared by casting the powder of silver nanoparticles on a glass slide and subsequently airdrying it under ambient conditions. The pattern was recorded by $\mathrm{CuK} \alpha$ radiation with $\lambda$ of $1.5406 \AA$ at a voltage of $40 \mathrm{kV}$ and current of $15 \mathrm{~mA}$ with a scan rate of $10^{\circ}$ \% min. Presence of functional groups present in AgNPs was determined by using FTIR (ALPHA BRUKER Eco-ATR).

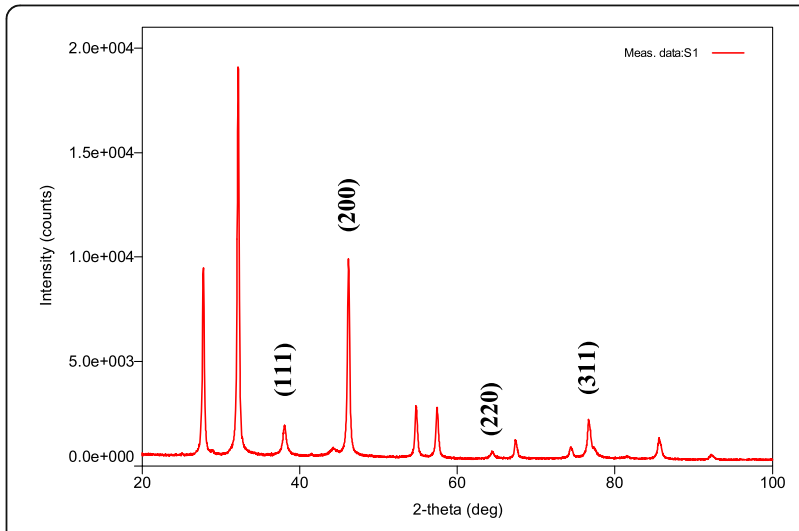

Fig. 8 X-ray diffractogram of AgNPs 


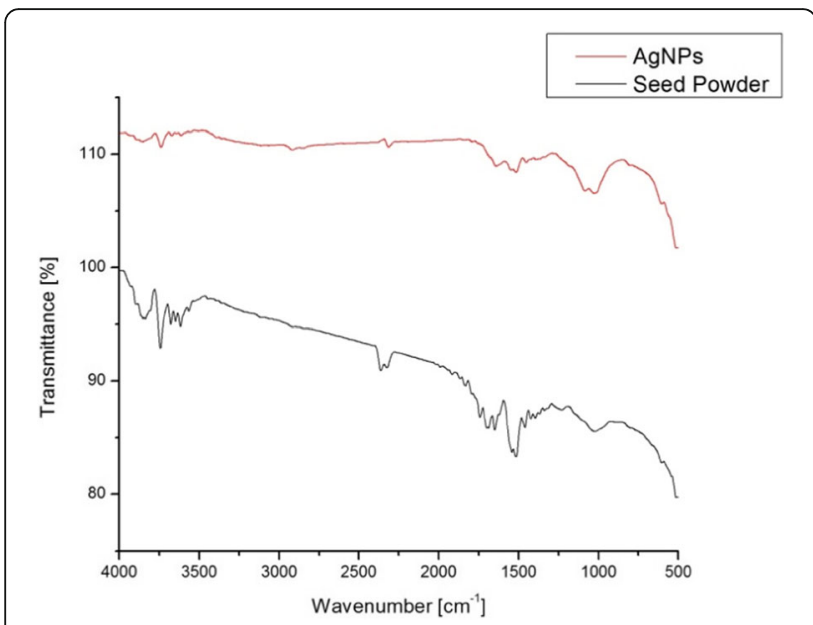

Fig. 9 FTIR spectra of AgNPs

Four per centimeter resolution was taken in all spectra with $500-4000 \mathrm{~cm}^{-1}$ IR range.

\section{Antibacterial assay}

Well diffusion method is commonly used to check the antimicrobial activity of the nanoparticles. The antimicrobial activity of synthesized AgNPs was checked using this method. Three microorganisms, namely $E$. coli, Bacillus cereus, and Staphylococcus aureus were used for this purpose. $1 \mathrm{mg} / \mathrm{ml}$ solution of AgNPs was made in Milli Q water and was sonicated properly. Overnight grown culture in Luria-Bertani broth of the mentioned microorganisms was taken and diluted to an optical density of 1 . Diluted bacterial suspension $(500 \mu \mathrm{l})$ was spread uniformly on three different Luria-Bertani agar plates for three different microorganisms. After spreading, two wells were cut on each plate using well borer of approximately $10 \mathrm{~mm}$ diameter. One well was filled with $50 \mu \mathrm{g}$ and the other with $100 \mu \mathrm{g}$ of AgNPs solution in all the three plates. The plates were incubated at $37^{\circ} \mathrm{C}$ for $24 \mathrm{~h}$, and the zone of inhibition was measured.
Determination of minimum inhibitory concentration (MIC) Minimum inhibitory concentration is defined as the minimum concentration of the material that inhibits the growth of the particular microorganisms. The method is based on growing microorganisms at varying concentrations of AgNPs in suspension. Sterile test tubes, containing $5 \mathrm{ml}$ of Luria-Bertani broth were taken. In the test tubes, varying concentrations of AgNPs were added and one test tube was taken as control. Then, the test tubes including the control were inoculated with an equal volume $(200 \mu \mathrm{l})$ of freshly prepared bacterial suspension diluted to an optical density of 0.5 . The inoculated test tubes were incubated in a shaker incubator at $250 \mathrm{rpm}$ and $37^{\circ} \mathrm{C}$ for $24 \mathrm{~h}$. The next day, absorbance was taken using UV-visible spectrophotometer at $600 \mathrm{~nm}$, and the graph was plotted against optical density and the concentration of AgNPs. The concentration giving the least optical density corresponds to MIC of silver nanoparticles for that particular microorganism. The above method is repeated with all the three microorganisms, namely E. coli, Bacillus cereus, and Staphylococcus aureus.

\section{Determination of the effect of AgNPs on leakage of membrane}

In this leakage of reducing sugars and proteins through the membrane was determined. For this, overnight grown cultures of E. coli, Bacillus cereus, and Staphylococcus aureus were taken, and $2 \mathrm{ml}$ sample was withdrawn from each culture and was marked as $0 \mathrm{~h}$ sample. One milliliter of AgNPs solution $(1 \mathrm{mg} / \mathrm{ml})$ was added to each culture and was incubated at $200 \mathrm{rpm}$ and $37^{\circ} \mathrm{C}$. Now, the sample was withdrawn after $2 \mathrm{~h}, 4 \mathrm{~h}$, and $6 \mathrm{~h}$ from each culture. All the samples were centrifuged at 10,000 rpm for $5 \mathrm{~min}$. Pellet was discarded and the supernatant was preserved at $30^{\circ} \mathrm{C}$ immediately, and the concentration of reducing sugar and proteins were determined by DNS and Bradford's method, respectively, as soon as possible.

\section{Results and discussion}

Nanoparticles synthesis initiates once the $T$. grandis seeds extract was introduced into $1 \mathrm{mM} \mathrm{AgNO}$ s solution. The

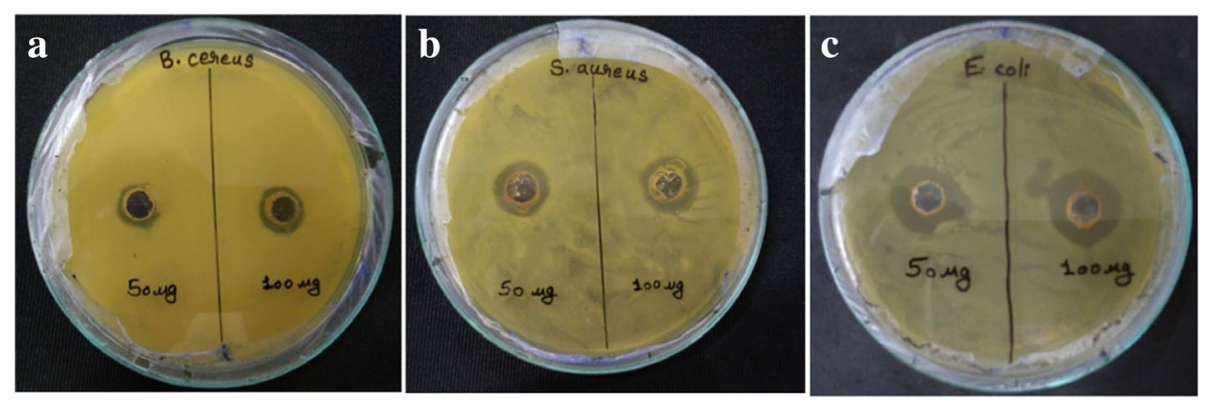

Fig. 10 Zone of inhibition of AgNPs against [(a) B. cereus, (b) S. aureus, and (c) E. coli] 
Table 1 Antimicrobial activity of AgNPs

\begin{tabular}{|c|c|c|c|}
\hline \multirow[b]{2}{*}{ Concentration of AgNPs } & \multicolumn{3}{|c|}{ Diameter of zone of inhibition (mm) } \\
\hline & B. cereus & S. aureus & E. coli \\
\hline $50 \mu \mathrm{g}$ & 12 & 16 & 17 \\
\hline $100 \mu \mathrm{g}$ & 14 & 17 & 20 \\
\hline
\end{tabular}

gradual color change of $\mathrm{AgNO}_{3} / T$. grandis solution from colorless to yellow and finally to reddish brown indicates the formation of silver nanoparticles as shown in Fig. 1. This color change is due to the surface plasmon vibration, an optical property which is unique to the noble metals (Ibrahim 2015). The formation of AgNPs was further confirmed by using UV-visible spectroscopy, scanning electron microscopy, field emission scanning electron microscopy, energy-dispersive X-ray spectroscopy, transmission electron microscopy, X-ray diffraction, and Fourier transform infrared spectroscopy.

Formation of the nanoparticles in the aqueous solution was further confirmed by the UV-visible spectroscopy. The wavelength scale was fixed between 300 and $600 \mathrm{~nm}$, and the solution was scanned in this range. Maximum absorbance at $440 \mathrm{~nm}$ was observed, which is characteristic of silver nanoparticles (Bahuguna et al. 2016). The curve (Fig. 2) shows an increase in absorbance with the increase in incubation time (30 min, $45 \mathrm{~min}$, and $1 \mathrm{~h}$ ) of silver nitrate and seed extract.

Scanning electron microscopy images of the lyophilized silver nanoparticles showed mostly spherical particles of a size below $100 \mathrm{~nm}$ as shown in Fig. 3. The image was a blurred one as the SEM present at the institute was not able to take images of particles below $100 \mathrm{~nm}$. Therefore, FESEM of the nanoparticles was done.
FESEM (Fig. 4) clearly shows the presence of synthesized nanoparticles. The nanoparticles were oval, spherical in shape. Most of the nanoparticles were aggregated, and few individual particles were also observed (Suman et al. 2013).

Elemental mapping of AgNPs by FESEM-EDX shows the presence of $94 \%$ of $\mathrm{Ag}$ and $6 \%$ of oxides as shown in Fig. 5. Elemental analysis of AgNPs was confirmed by EDX as shown in Fig. 6. A strong signal of the peak was observed at $3 \mathrm{KeV}$ which is typical for absorption of metallic silver nanoparticles. The absence of other elements confirms the purity of prepared nanoparticles.

Further, an insight into the morphology and size details of AgNPs was provided by transmission electron microscopy. TEM image as shown in Fig. 7 clearly demonstrates that the AgNPs were spherical in shape. The image shows agglomerates of small grains and some dispersed nanoparticles, confirming the results obtained by SEM and FESEM (Guzmán et al. 2009). The synthesized AgNPs were in the range of $10-30 \mathrm{~nm}$. The selected area diffraction pattern (Fig. 7, inset) confirms the face-centered cubic (fcc) crystalline structure of metallic silver.

Figure 8 shows the XRD pattern of silver nanoparticles which confirmed the crystalline nature of AgNPs. The four distinct diffraction peaks at $2 \theta$ values of $38.05 \theta$, $44.23 \theta, 64.41 \theta$, and $76.66 \theta$ can be indexed to the $(11$

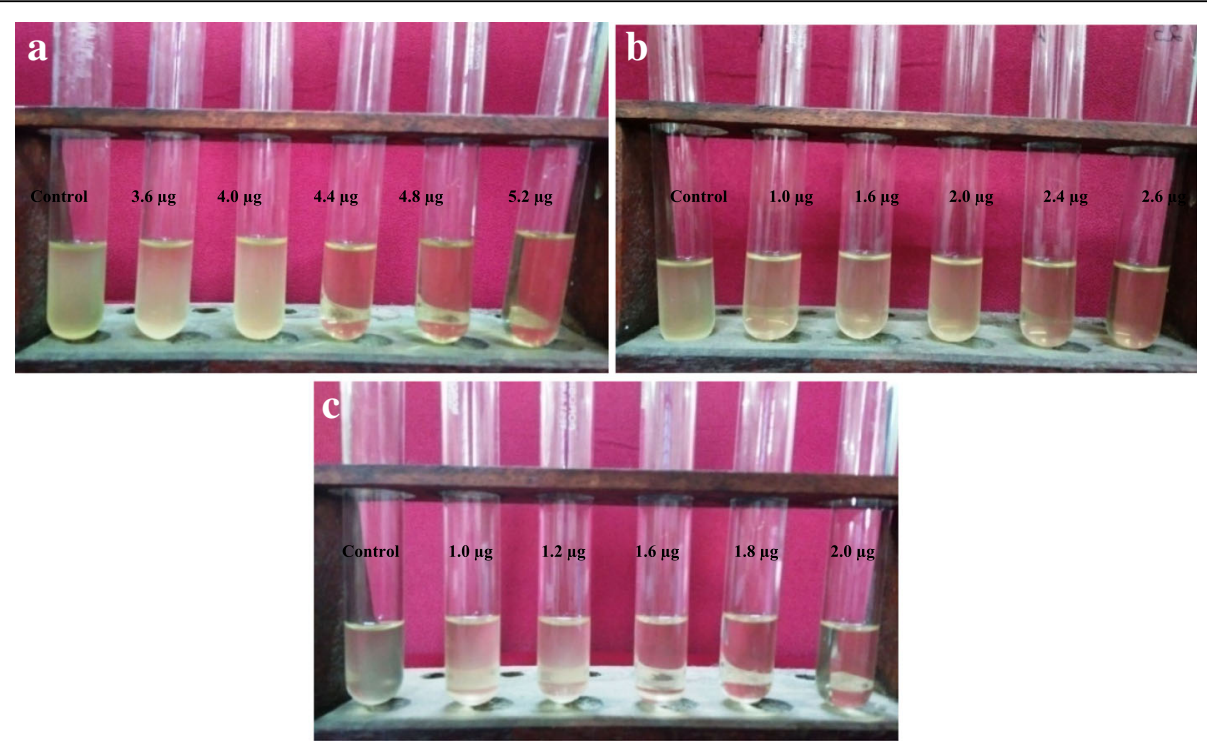

Fig. 11 Broth dilution assay to detect MIC against [(a) B. cereus, (b) S. aureus, and (c) E. coli] 

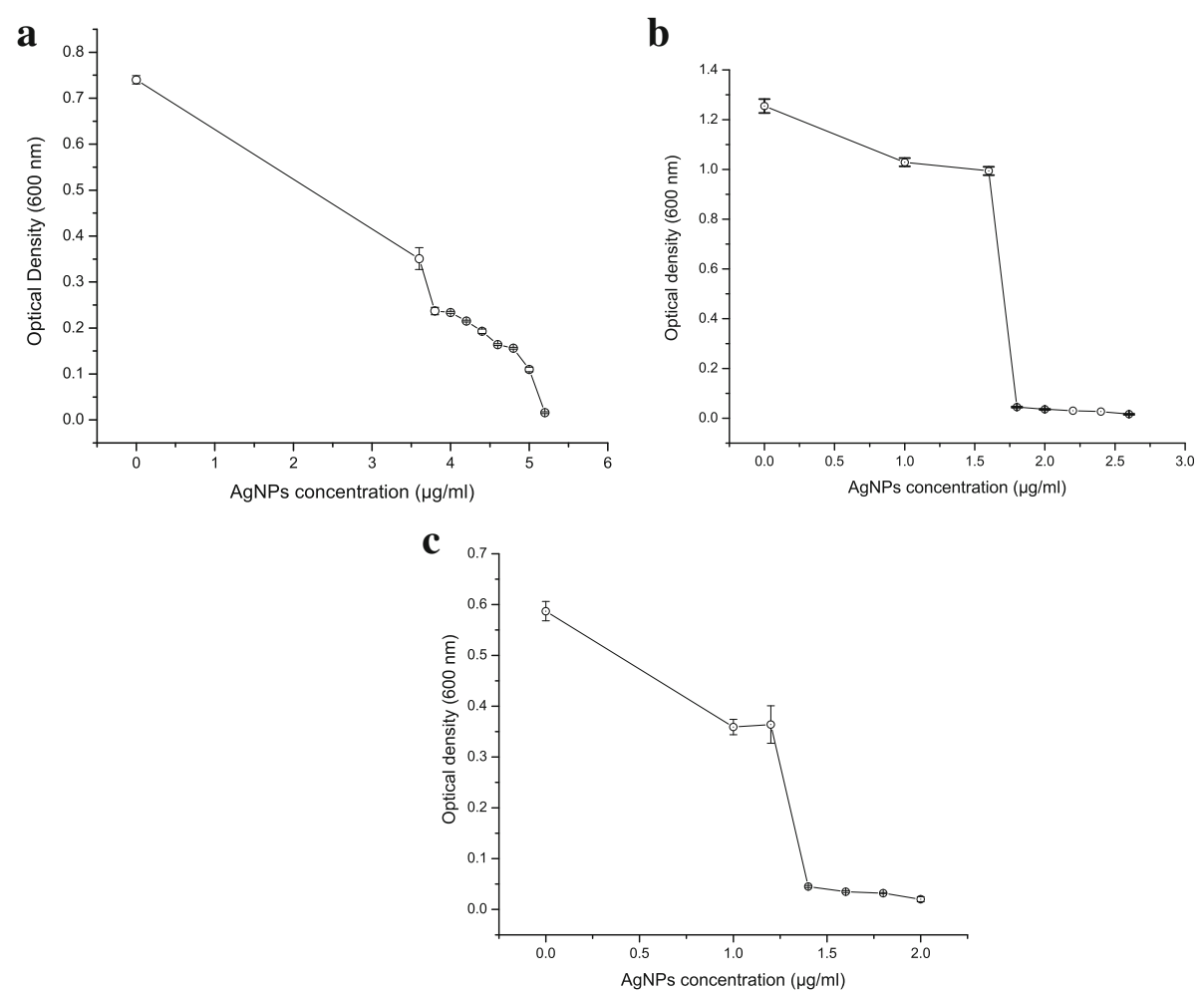

Fig. 12 Average bacterial growth after $24 \mathrm{~h}$ with varying concentrations of AgNPs. [(a) B. cereus, (b) S. aureus, and (c) E. coli]
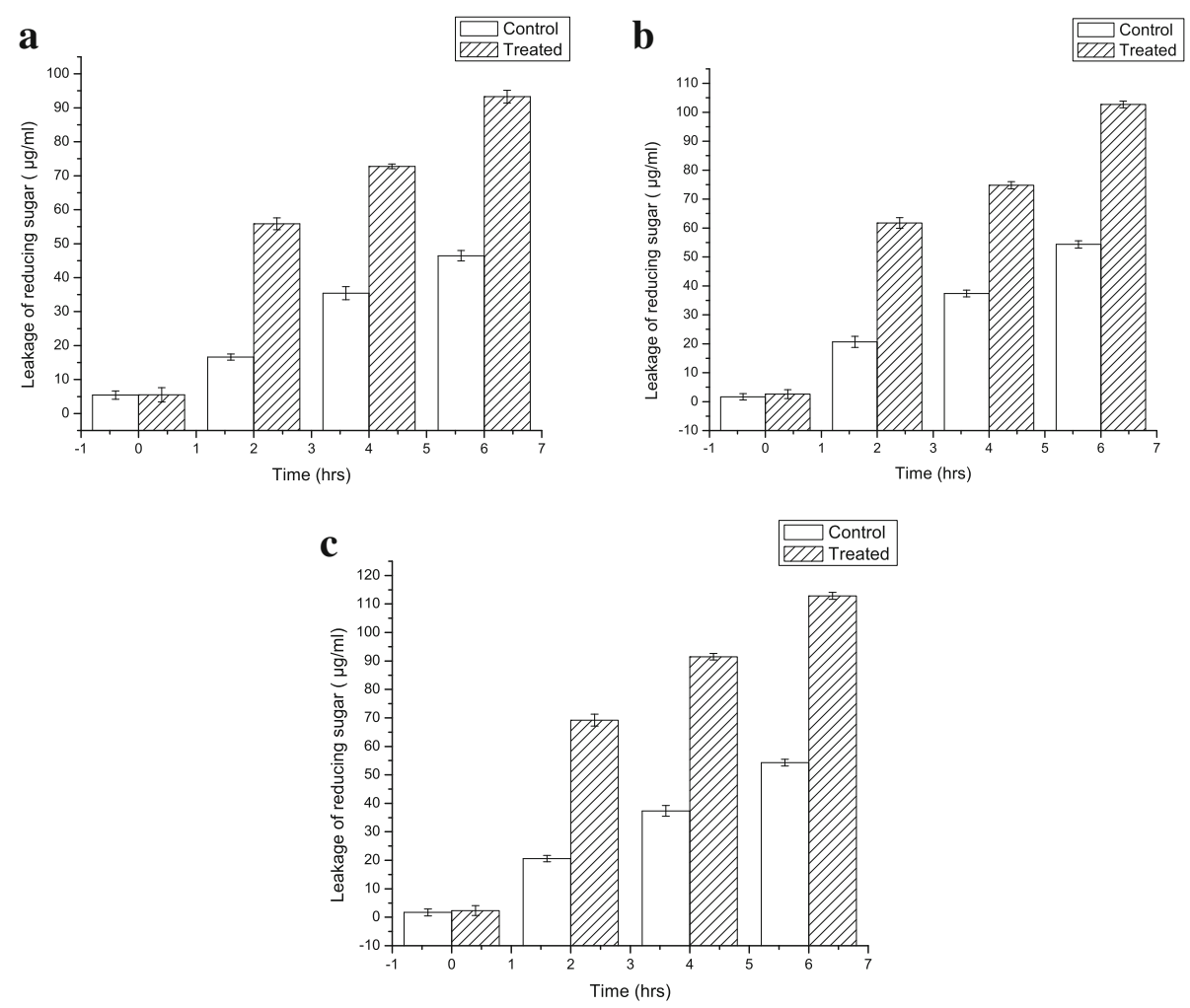

Fig. 13 Leakage of reducing sugar from (a) B. cereus, (b) S. aureus, and (c) E. coli cells treated with AgNPs 

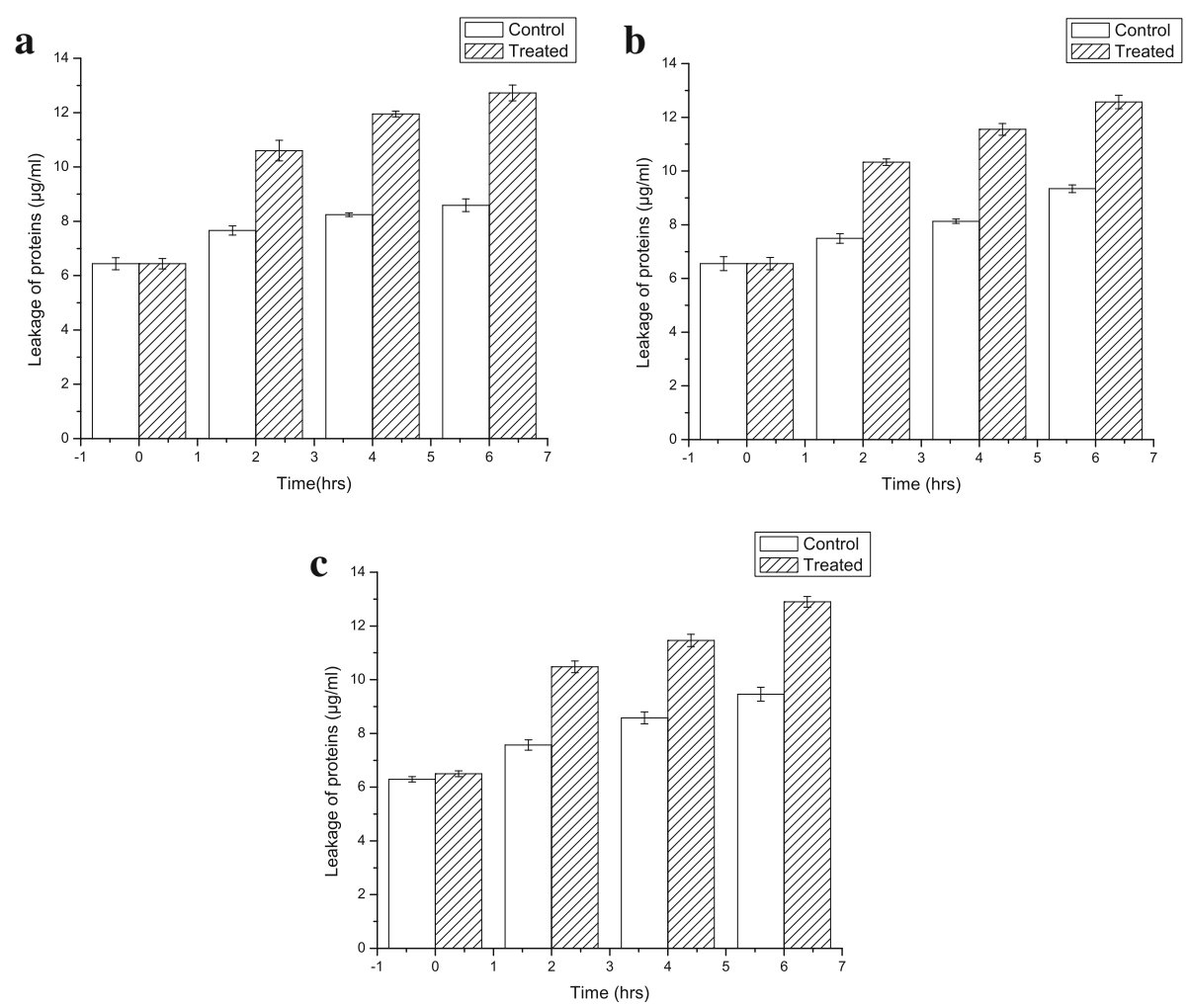

Fig. 14 Leakage of proteins from (a) B. cereus, (b) S. aureus, and (c) E. coli cells treated with AgNPs

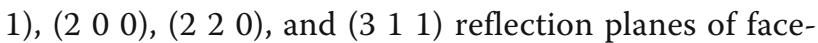
centered cubic structure of silver. In addition to the Bragg peaks representative of silver nanocrystals, additional peaks were also observed at $27.77 \theta, 32.18 \theta, 46.17 \theta$, and $54.752 \theta$. Presence of these peaks was due to seed extract which contains organic compounds and is responsible for the reduction of silver ions and stabilization of resultant nanoparticles (Ibrahim 2015).

FTIR measurements were carried out to identify the major functional groups in the seed extract and their possible involvement in the synthesis and stabilization of silver nanoparticles. The spectrum of seed powder and synthesized AgNPs is represented in Fig. 9. Seed extract showed several peaks indicating the complex nature of the biological material. The bands appearing at 1745 , 1643,1508 , and $1038 \mathrm{~cm}^{-1}$ were assigned to stretching vibration of $\mathrm{C}=\mathrm{O}$ bond of carboxylic acid or ester, $\mathrm{N}-$ $\mathrm{C}=\mathrm{O}$ amide bond of proteins, nitro compounds, $\mathrm{C}-\mathrm{N}$ amine bond, respectively. There was a shift in the peaks in synthesized silver nanoparticles which suggests that functional groups of seed extract participate in the formation of AgNPs.

The synthesized AgNPs were investigated for antimicrobial activity by using well diffusion method. Growth inhibition was observed after $24 \mathrm{~h}$ on plates loaded with 50 and $100 \mu \mathrm{g}$ of AgNPs (Fig. 10). Bacterial growth suppression around the well was due to the release of diffusible inhibitory compounds, i.e., silver nanoparticles.

From Table 1, it is evident that Gram-negative bacteria (E. coli) show a higher zone of inhibition, in comparison to Gram-positive bacteria (B. cereus and $S$. aureus) at the same concentration of AgNPs. This difference could be explained by variation in the composition of the cell wall of Gram-positive and Gram-negative bacteria. In Gram-positive bacteria, the cell wall is constituted of a thick peptidoglycan layer, consisting of short peptide cross-linked linear polysaccharide chains. This leads to a more rigid structure, increasing difficulties in penetration of the silver nanoparticles. On the other hand, the Gram-negative bacteria's cell wall is composed of a thinner peptidoglycan layer (Shrivastava et al. 2007).

After confirmation of antimicrobial activity of synthesized AgNPs through well diffusion assay, minimum inhibitory concentration (MIC) of AgNPs against B. cereus, $S$. aureus, and E. coli was determined. Broth dilution method is the most commonly used technique to determine the MIC of antimicrobial agents against different microorganisms (Fig. 11). After $24 \mathrm{~h}$ of incubation, no growth of $B$. cereus, $S$. aureus, and $E$. coli was seen in the test tubes supplemented with $5.2,2.6$, and $2.0 \mu \mathrm{g} / \mathrm{ml}$ of silver nanoparticles, and the optical density was $0.016,0.016$, and 0.02 , respectively (Fig. 12). 
MIC results are in relation to the fact that a larger zone of inhibition corresponds to smaller minimum inhibitory concentration (Mohanty et al. 2010).

The action of the mechanism of silver nanoparticles on microorganisms is still a topic of debate. Figures 13 and 14 reveal that AgNPs could enhance the permeability of the membrane, and thus leakage of reducing sugars and proteins. There was an increase in the release of sugar and proteins in all the microorganisms as the incubation time increases. At $0 \mathrm{~h}$, in control and treated samples, amount of sugar and proteins were almost the same, as there was no time of contact between AgNPs and microorganisms. But at 2, 4, and $6 \mathrm{~h}$ amount of sugar and proteins were higher as compared with control in all the cases, which suggests that AgNPs may have expedited leakage of sugar and proteins from the cytoplasm of microorganisms.

The maximum amount of sugars and proteins is released by E. coli (112.86 and $12.9 \mu \mathrm{g} / \mathrm{ml}$, respectively) when treated with AgNPs. Whereas, the least amount is released by $B$. cereus.

\section{Conclusion}

In conclusion, a simple, safe, and one-step process is utilized for the synthesis of silver nanoparticles by using the Tectona grandis seed extract. Seed extracts act as a reducing agent for nanoparticles synthesis. No chemical reagent or surfactant template is required in the process, which consequently established the bioprocess with the advantage of being environmentally friendly. TEM analysis revealed that nanoparticles were in the range of $10-30 \mathrm{~nm}$ and spherical. SAED and XRD pattern confirmed the crystalline nature of AgNPs. Synthesized nanoparticles showed antimicrobial activity which was investigated by agar well diffusion method against $B$. cereus, S. aureus, and E. coli. Minimum inhibitory concentration against these pathogens was determined by the broth dilution method which was found to be 5.2, 2.6, and $2.0 \mu \mathrm{g} / \mathrm{ml}$ for B. cereus, S. aureus, and E. coli, respectively. MIC results were in accordance with the zone of inhibition, i.e., more zone of inhibition less MIC value and vice-versa. Mechanism of action of antimicrobial activity was found to be the change in permeability of membrane by detecting the release of reducing sugars and proteins through leaky membrane, which was detected by DNS and Bradford's method, respectively.

\begin{abstract}
Abbreviations
AgNPs: Silver nanoparticles; EDS: Energy-dispersive spectra; FESEM: Field emission scanning electron microscopy; FTIR: Fourier transformation infrared; MIC: Minimum inhibitory concentration; SEM: Scanning electron microscopy; TEM: Transmission electron microscopy
\end{abstract}

\section{Acknowledgements}

We thank Central Instrument Facility, IIT-BHU for providing us the necessary instrumentation facilities. We are grateful to the Ministry of Human Resource and Development (MHRD), India for financial aid.
Availability of data and materials

Data sharing is not applicable. It will be shared if needed.

\section{Declaration}

This submitted work has not been published previously (except in the form of an abstract, and an academic thesis), and is not under consideration for publication elsewhere, it's publication is approved by all authors and tacitly or explicitly by the responsible authorities where the work was carried out, and if accepted, it will not be published elsewhere in the same form, in English or in any other language, including electronically without the written consent of the copyright holder. The authors declare that they have no competing interests.

\section{Authors' contributions}

AR carried out all the experiments mentioned in the manuscript as this was his M.Tech dissertation work. JR helped to draft the manuscript. MD is the Senior Professor and was the supervisor of the dissertation work. All authors read and approved the final manuscript.

\section{Competing interests}

The authors declare that they have no competing interests.

\section{Publisher's Note}

Springer Nature remains neutral with regard to jurisdictional claims in published maps and institutional affiliations.

Received: 13 August 2018 Accepted: 28 December 2018

Published online: 22 January 2019

\section{References}

Asthana A, et al. Silver Nanoparticle Entrapped Calcium-Alginate Beads for Fe (II) Removal via Adsorption. in Macromolecular Symposia: Wiley Online Library; 2016.

Bahuguna G, et al. Green synthesis and characterization of silver nanoparticles using aqueous petal extract of the medicinal plant Combretum indicum. Mat Res Express. 2016;3(7):075003.

Bar $\mathrm{H}$, et al. Green synthesis of silver nanoparticles using seed extract of Jatropha curcas. Colloids Surf A Physicochem Eng Asp. 2009;348(1-3):212-6.

Das SK, et al. Silver-nano biohybride material: synthesis, characterization and application in water purification. Bioresour Technol. 2012;124:495-9.

Diallo A, et al. Effect of Tectona grandis on phenylhydrazine-induced anaemia in rats. Fitoterapia. 2008;79(5):332-6.

Feng $\mathrm{QL}$, et al. A mechanistic study of the antibacterial effect of silver ions on Escherichia coli and Staphylococcus aureus. J Biomed Mater Res. 2000; 52(4):662-8

Guzmán MG, Dille J, Godet S. Synthesis of silver nanoparticles by chemical reduction method and their antibacterial activity. Int J Chem Biomol Eng. 2009:2(3):104-11

He $Y$, et al. Green synthesis of silver nanoparticles by Chrysanthemum morifolium Ramat. extract and their application in clinical ultrasound gel. Int J Nanomedicine. 2013;8:1809.

Ibrahim HM. Green synthesis and characterization of silver nanoparticles using banana peel extract and their antimicrobial activity against representative microorganisms. J Radiat Res Appl Sci. 2015;8(3):265-75.

Indira E, Mohanadas K. Intrinsic and extrinsic factors affecting pollination and fruit productivity in teak (Tectona grandis Linn. f.). Indian J Genet Plant Breeding. 2002;62(3):208-14.

Jaybhaye D, Varma S, Gagne N. Effect of Tectona grandis Linn. seeds on hair growth activity of albino mice. Int J Ayurveda Res. 2010;1(4):211.

Kowshik M, et al. Extracellular synthesis of silver nanoparticles by a silver-tolerant yeast strain MKY3. Nanotechnology. 2002;14(1):95.

Krishna MS, Jayakumaran N. Antibacterial, cytotoxic and antioxidant potential of different extracts from leaf, bark and wood of Tectona grandis. Int J Pharm Sci Res. 2010;2:155-8.

Kumar VG, et al. Facile green synthesis of gold nanoparticles using leaf extract of antidiabetic potent Cassia auriculata. Colloids Surf B: Biointerfaces. 2011; 87(1):159-63.

Lin S, et al. Silver nanoparticle-alginate composite beads for point-of-use drinking water disinfection. Water Res. 2013;47(12):3959-65.

Matsumura $Y$, et al. Mode of bactericidal action of silver zeolite and its comparison with that of silver nitrate. Appl Environ Microbiol. 2003;69(7):4278-81. 
Mohanty A, et al. Physico-chemical and antimicrobial study of polyherbal formulation. Int J Comprehensive Pharm. 2010;1(4):1-3.

Mukherjee $\mathrm{P}$, et al. Fungus-mediated synthesis of silver nanoparticles and their immobilization in the mycelial matrix: a novel biological approach to nanoparticle synthesis. Nano Lett. 2001;1(10):515-9.

Natarajan K, Selvaraj S, Murty VR. Microbial production of silver nanoparticles. Dig J Nanomater Biostruct. 2010;5(1):135-40.

Neamatallah A, et al. An extract from teak (Tectona grandis) bark inhibited Listeria monocytogenes and methicillin resistant Staphylococcus aureus. Lett Appl Microbiol. 2005;41(1):94-6.

Ping $\mathrm{H}$, et al. Visual detection of melamine in raw milk by label-free silver nanoparticles. Food Control. 2012;23(1):191-7.

Prakash P, et al. Green synthesis of silver nanoparticles from leaf extract of Mimusops elengi, Linn. for enhanced antibacterial activity against multi drug resistant clinical isolates. Colloids Surf B: Biointerfaces. 2013;108:255-9.

Qin $Y$, et al. Size control over spherical silver nanoparticles by ascorbic acid reduction. Colloids Surf A Physicochem Eng Asp. 2010;372(1-3):172-6.

Rashid MU, Bhuiyan MKH, Quayum ME. Synthesis of silver nano particles (Ag-NPs) and their uses for quantitative analysis of vitamin C tablets. Dhaka Univ J Pharm Sci. 2013;12(1):29-33.

Sastry $\mathrm{M}$, et al. Biosynthesis of metal nanoparticles using fungi and actinomycete. Curr Sci. 2003:85(2):162-70.

Sathishkumar M, et al. Cinnamon zeylanicum bark extract and powder mediated green synthesis of nano-crystalline silver particles and its bactericidal activity. Colloids Surf B: Biointerfaces. 2009;73(2):332-8.

Shrivastava $S$, et al. Characterization of enhanced antibacterial effects of nove silver nanoparticles. Nanotechnology. 2007;18(22):225103.

Song KC, et al. Preparation of colloidal silver nanoparticles by chemical reduction method. Korean J Chem Eng. 2009;26(1):153-5.

Suman T, et al. Biosynthesis, characterization and cytotoxic effect of plant mediated silver nanoparticles using Morinda citrifolia root extract. Colloids Surf B: Biointerfaces. 2013;106:74-8.

Thompson DG, et al. Ultrasensitive DNA detection using oligonucleotide-silver nanoparticle conjugates. Anal Chem. 2008;80(8):2805-10.

Vigneshwaran $\mathrm{N}$, et al. Functional finishing of cotton fabrics using silver nanoparticles. J Nanosci Nanotechnol. 2007a;7(6):1893-7.

Vigneshwaran $\mathrm{N}$, et al. Biological synthesis of silver nanoparticles using the fungus Aspergillus flavus. Mater Lett. 2007b;61(6):1413-8.

Wiley B, et al. Polyol synthesis of silver nanoparticles: use of chloride and oxygen to promote the formation of single-crystal, truncated cubes and tetrahedrons. Nano Lett. 2004:4(9):1733-9.

\section{Submit your manuscript to a SpringerOpen ${ }^{\circ}$ journal and benefit from:}

- Convenient online submission

- Rigorous peer review

- Open access: articles freely available online

- High visibility within the field

- Retaining the copyright to your article

Submit your next manuscript at $\boldsymbol{\nabla}$ springeropen.com 